\title{
Familial grouped pigmentation of the retinal pigment epithelium
}

\author{
PAUL T V M DE JONG' AND J WILLEM DELLEMAN ${ }^{2}$ \\ From the 'Department of Ophthalmology, Erasmus University Rotterdam, Eye Hospital, Rotterdam, and the \\ ${ }^{2}$ Department of Ophthalmogenetics, Netherlands Ophthalmic Research Institute, Amsterdam, The Netherlands
}

SUMMARY Grouped pigmentation of the retinal pigment epithelium was found in a father and his son. They had a normal resting potential on the electro-oculogram, but the son had a lower normal light rise. We believe this is the first description of familial grouped pigmentation.

Grouped pigmentation of the retinal pigment epithelium has been known for over 100 years, ${ }^{1}$ but it was not until 1911 that $\mathrm{Hög}^{2}$ used this name to describe clusters of pigment in the retina. The entity has also been called melanosis retinae, bear or animal tracks, and naevoid pigmentation of the fundus. Grouped pigmentation has always been described as being of sporadic nature, though several authors looked for a familial occurrence. ${ }^{34}$ The only published description of familial grouped pigmentation was by Forgacs and Bozin. ${ }^{5}$ Deutman ${ }^{6}$ has pointed out that the two sisters described by them possibly did not have grouped pigmentation. In our opinion the description and drawings in their article are more in keeping with naevi that have a slightly hypopigmented border like the halo naevi often found in the skin. Recently we examined a father and son who both had classic grouped pigmentation in their retina.

\section{Case reports}

The proband (Fig. 1 case III-3) came to the outpatient department because he had lost his glasses. From age 7 on he was known to have had subnormal visual acuity, attributed to refraction amblyopia. $\mathrm{He}$ was healthy and had never taken medicine as a routine.

On examination the visual acuity was right eye 0.5 with +7.5 sph -2.25 axis $15^{\circ}$; left eye 0.8 with +5.5 sph -1.0 axis $170^{\circ}$. The anterior segments and media were clear. In both fundi extensive areas with grouped pigmentation of the retina were visible (Fig. 2). He had central fixation in each eye. Fluorescein angiography revealed blockage of background

Correspondence to Professor Dr P T V M de Jong, Eye Hospital, Schiedamsevest 180, 3011 BH Rotterdam, The Netherlands. fluorescence without any leakage on the late phases. The pattern electroretinogram showed normal cone and slightly subnormal rod (RE $80 \%$, LE $70 \%$ ) responses. The pattern cortical evoked potentials had normal amplitudes and latencies. The electrooculogram resulted in a light peak-dark trough ratio in the lower normal range (RE 1.76, LE 1.75). The electrophysiological techniques have been described elsewhere. ${ }^{7}$ In our set-up the mean light peak-dark trough ratio is 2.20 with a lower limit of 1.60 (2 SD). Kinetic Goldmann perimetry revealed no abnormalities.
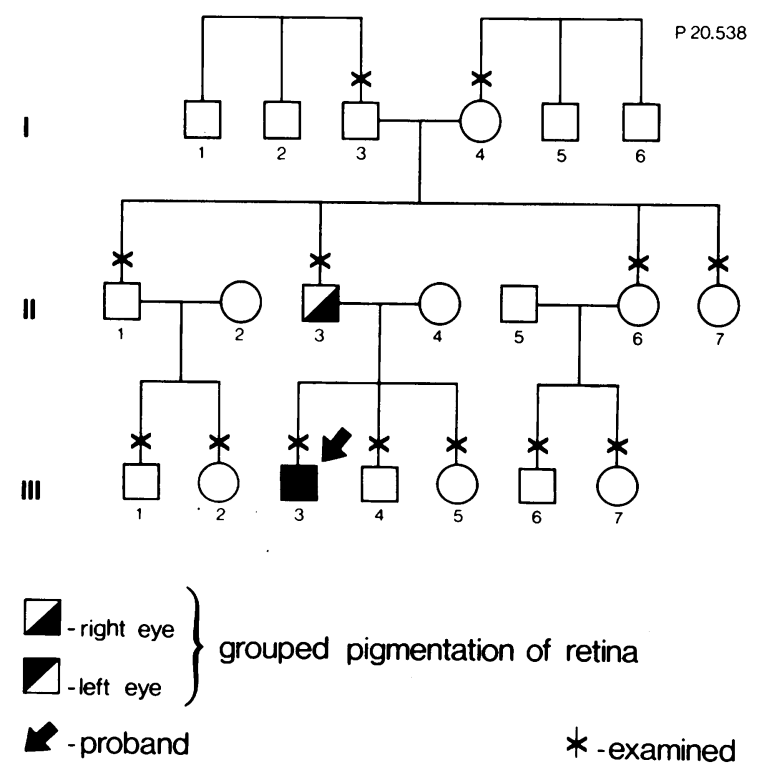

Fig. 1 Pedigree of family with grouped pigmentation of the retinal pigment epithelium. 

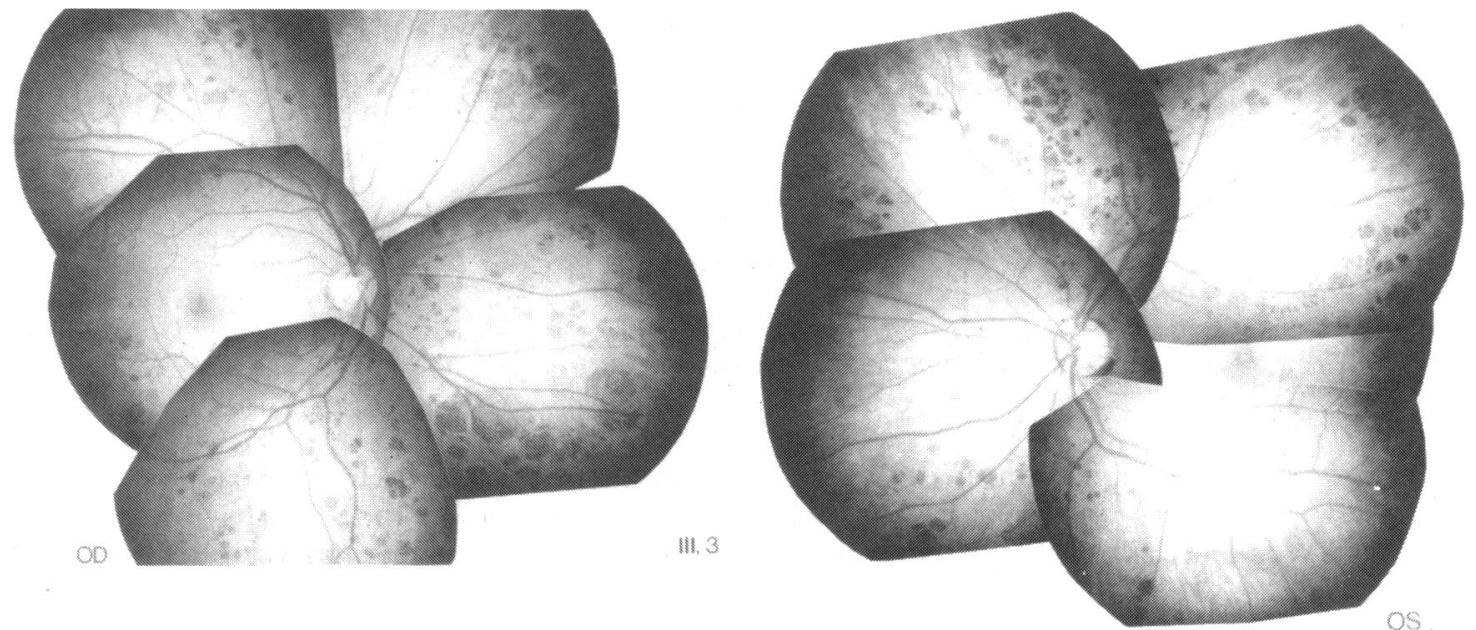

Fig. 2 Right and left eye of proband, case III-3. Note grouped pigmentations in all quadrants of both eyes.

His father, case II-3, had no eye complaints but simply accompanied his son to the outpatient department. He consented to allow us to examine his eyes. In both eyes his visual acuity was 1.5 with $+0.5 \mathrm{sph}$. In the right fundus grouped pigmentation of the retinal pigment epithelium was seen in an area inferior to the optic disc (Fig. 3). These lesions were less pigmented than in his son's fundus. The fluorescein angiogram had the same characteristics as his son's. His electro-oculogram gave a normal resting potential and a good light rise (RE 2.29, LE 2.11 light peak-dark trough ratio).

Case III-4 had OU full vision with $+0.50 \mathrm{sph}$. In

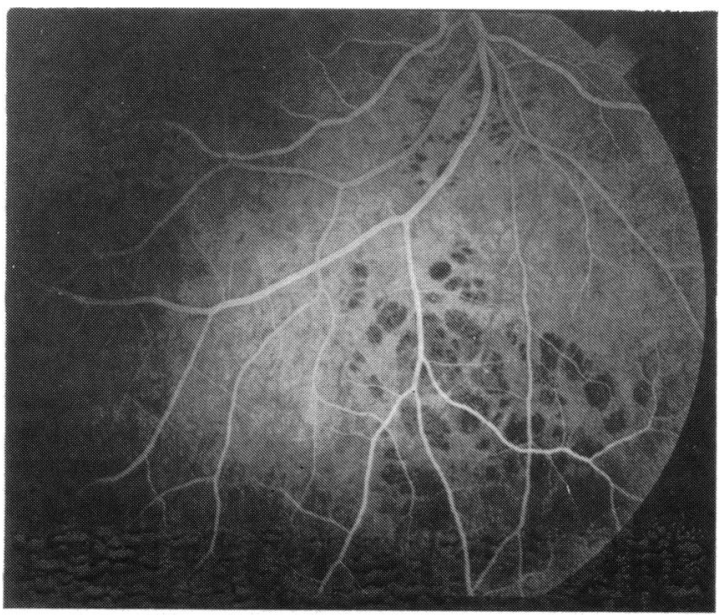

Fig. 3 Case II-3. Fluorescein angiogram, arteriovenous phase. Grouped pigmentation in area below right optic disc. Noleakage on late pictures. both eyes discretely pigmented spots were visible at the periphery not clearly resembling grouped pigmentation.

Case III-5 also had full vision OU and was emmetropic. She had no pigmentary anomalies.

It was not possible for the other family members, some living abroad, to be examined by the authors. They all had a dilated fundus examination by their own ophthalmologists, who were specifically asked by the authors to look for grouped pigmentations. None of them had grouped pigmentation or hypermetropia greater than $+0 \cdot 75$.

\section{Discussion}

We believe this to be the first report of familial occurrence of unquestionable grouped pigmentation of the retinal pigment epithelium. The exact prevalence of this benign abnormality is unknown. The Framingham eye study ${ }^{8}$ did not specifically look for all kinds of fundus abnormalities. The investigator, however, while looking for macular degeneration, was required to record pigment disturbances in the macula, the perimacular area, or of unknown location in the eyes with visual acuity 20/30 or worse. In 5253 eyes no mention of grouped pigmentation was made. We found only one report ${ }^{4}$ in which it was stated that three cases were seen in an examination of 2500 eyes without any further epidemiological data. If it is assumed that the reasons for seeing an ophthalmologist were the same in 1891 as in 1986 and that the prevalence of grouped pigmentation has remained constant, we could calculate that the prevalence nowadays would be $0 \cdot 12 \%$ in an ophthalmic population. The chances that both a father and 
his son would have grouped pigmentation by coincidence would be smaller than 1:1000000, because the father was not an ophthalmic patient but simply an accompanying person. It thus seems likely that grouped pigmentation is a disorder of autosomal dominant inheritance with variable expression.

This might place grouped pigmentation among the pattern dystrophies as a hereditary disorder of the retinal pigment epithelium with a normal or slightly subnormal visual acuity, blockage of background fluorescence on the angiogram with no leakage on the late phases, and an electro-oculogram in the lower normal range. So far as we know what constitutes a pattern dystrophy has never been exactly defined. Some people claim that a bilateral, symmetrical, progressive disorder should be present, but in many cases described as pattern dystrophy these conditions were not met.

The subnormal visual acuity of our proband may possibly be attributed to his hypermetropic astigmatism resulting in amblyopia. From an early age he was known to have subnormal visual acuity. We think it unlikely that this acuity was affected by the grouped pigmentation, as he had no abnormal pigmentation in his macula and we found a report stating that the photoreceptors overlying the pigmented areas in grouped pigmentation showed only post mortem changes. ${ }^{10}$ On the other hand hypermetropia has previously been mentioned in relation to grouped pigmentation. ${ }^{4}$

It has been suggested that grouped pigmentation and congenital hypertrophy of the retinal pigment epithelium are different expressions of the same disorder. ${ }^{11}{ }^{12}$ We disagree because of the difference in morphology and, because in contrast to the cases with grouped pigmentation, the congenital hypertrophy cases showed lack of photoreceptors above the lesions, ${ }^{13}$ abnormal visual fields, ${ }^{113}$ reported growth,$^{14}$ and abnormal vessels above the hypertrophy. ${ }^{15}$ Congenital hypertrophy of the retinal pigment epithelium, however, has also been shown to be hereditary in cases of Gardner's syndrome ${ }^{16}$ and in one family with microcephaly and hyperreflexia. ${ }^{17}$

This family had no history of hereditary abnormalities. Grouped pigmentation has been associated with convergent squint, ${ }^{2}$ macular coloboma, ${ }^{18}$ and chondrodysplasia, ${ }^{19}$ but in the last case we think the description fits more that of pigment epithelial hypertrophy. We have personally seen a case of Rieger's anomaly and grouped pigmentation. ${ }^{20}$ Most patients with grouped pigmentation have no eye complaints, so that the pigmentation will often be a coincidental finding. It seems likely that systemic examination of sibships would disclose more familial cases of grouped pigmentation of the retinal pigment epithelium.

\section{References}

1 Mauthner L. Lehrbuch der Ophthalmoscopie. Wien: Tendler, 1868.

2 Höeg N. Die gruppierte Pigmentation des Augengrundes. Klin Monatsbl Augenheilkd 1911; 49: 49-77.

3 Tower P. Congenital grouped pigmentation of the retina. Arch Ophthalmol 1948; 39: 536-41.

4 Meunier A, Boursin P. La pigmentation groupée de la rétine. Bull Soc Belge Ophtalmol 1951; 99: 470-8.

5 Forgacs J, Bozin I. Manifestation familiale de pigmentations groupées de la région maculaire. Ophthalmologica 1966; 152: 364-8.

6 Deutman AF. In: Krill AE, ed. Hereditary retinal and choroidal diseases. Hagerstown: Harper and Row, 1977: 2: 730-6.

7 Arden GB, Barrada A, Kelsey JH. New clinical tests of retinal function based upon the standing potential of the eye. $\mathrm{Br} J$ Ophthalmol 1962; 46: 449-67.

8 Framingham Eye Study. Surv Ophthalmol 1980; 24 (suppl): 435.

9 Stephenson S. A peculiar form of retinal pigmentation. Trans Ophthalmol Soc UK 1891; 11: 77-82.

10 Shields JA, Tso MOM. Congenital grouped pigmentation of the retina. Histopathologic description and report of a case. Arch Ophthalmol 1975; 93: 1153-5.

11 Purcell JJ, Shields JA. Hypertrophy with hyperpigmentation of the retinal pigment epithelium. Arch Ophthalmol 1975; 93: 1122-6.

12 Feys J, Salvanet-Bouccara A. Hypertrophies de l'épithelium pigmentaire. J Fr Ophtalmol 1981; 4: 117-21.

13 Buettner $\mathrm{H}$. Congenital hypertrophy of the retinal pigment epithelium. Am J Ophthalmol 1975; 79: 177-89.

14 Norris JL, Cleasby GW. An unusual case of congenital hypertrophy of the retinal pigment epithelium. Arch Ophthalmol 1976; 94: 1910-1.

15 Cleary PE, Gregor Z, Bird AC. Retinal vascular changes in congenital hypertrophy of the retinal pigment epithelium. Br J Ophthalmol 1976; 60: 499-503.

16 Blair NP, Trempe CL. Hypertrophy of the retinal pigment epithelium associated with Gardner's syndrome. Am J Ophthalmol 1980; 90: 661-7.

17 Parke JT, Riccardi VM, Lewis RA, Ferrell RE. A syndrome of microcephaly and retinal pigmentary abnormalities without mental retardation in a family with coincidental autosomal dominant hyperreflexia. Am J Med Genet 1984; 17: 585-94.

$18 \mathrm{McGregor}$ IS. Macular coloboma with bilateral grouped pigmentation of the retina. Br J Ophthalmol 1945; 39: 132-6.

19 Collier M. Les manifestations oculaires associées à la dyschondroplasie d'Ollier. Bull Soc Ophthalmol Fr 1961; 4: 161-9.

20 de Jong PTVM, Delleman JW, Witmer JP, Zeilstra C. Rieger's anomaly with retinal pigmentations. Ophthalmologica $1979 ; 178$ : $107-8$.

Accepted for publication 14 April 1987. 